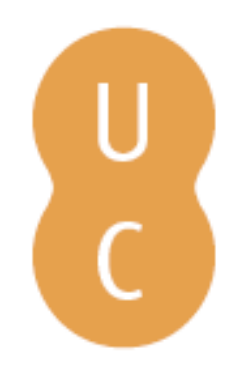

\title{
pompalina
}

\section{Poesia, hagiografia e política antes da Restauração de 1640}

Autor(es): Urbano, Carlota Miranda

Publicado por: Centro de Estudos Clássicos e Humanísticos; Imprensa da Universidade

URL

persistente: URI:http://hdl.handle.net/10316.2/31175

DOI: $\quad$ DOI:http://dx.doi.org/10.14195/978-989-8281-98-2_9

Accessed : $\quad$ 26-Apr-2023 14:17:29

A navegação consulta e descarregamento dos títulos inseridos nas Bibliotecas Digitais UC Digitalis, UC Pombalina e UC Impactum, pressupõem a aceitação plena e sem reservas dos Termos e Condições de Uso destas Bibliotecas Digitais, disponíveis em https://digitalis.uc.pt/pt-pt/termos.

Conforme exposto nos referidos Termos e Condições de Uso, o descarregamento de títulos de acesso restrito requer uma licença válida de autorização devendo o utilizador aceder ao(s) documento(s) a partir de um endereço de IP da instituição detentora da supramencionada licença.

Ao utilizador é apenas permitido o descarregamento para uso pessoal, pelo que o emprego do(s) título(s) descarregado(s) para outro fim, designadamente comercial, carece de autorização do respetivo autor ou editor da obra.

Na medida em que todas as obras da UC Digitalis se encontram protegidas pelo Código do Direito de Autor e Direitos Conexos e demais legislação aplicável, toda a cópia, parcial ou total, deste documento, nos casos em que é legalmente admitida, deverá conter ou fazer-se acompanhar por este aviso.

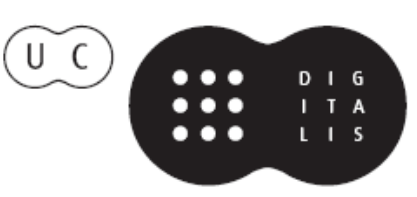


Colecção Autores Gregos e Latinos SérIe Ensaios

\section{Nair Castro Soares Margarida Miranda Carlota Miranda Urbano}

(Coord.)

HOMO ELOQVENS HOMO POLITICVS

A retórica e a CONSTRUÇão da CIDAdE NA IdAdE MÉdia E NO RENASCIMENTO 
Poesia, Hagiografia E POLÍtica ANTES DA Restauração de 1640

\author{
Carlota Miranda Urbano
}




\section{A Universidade de Coimbra e o desejo de autonomia da coroa portuguesa}

No primeiro quartel do séc. XVII ganhavam peso cada vez mais forte as vozes de descontentamento com o rumo a que a uniáo ibérica conduzira os destinos do reino de Portugal, que se via cada vez mais debilitado na sua soberania e autodeterminação. A cidade de Coimbra, centro cultural e universitário de então, de modo algum se alheava dos destinos políticos do reino. Naquela que fora a primeira capital pulsavam, pelo contrário, destemidos sentimentos e vontades de recuperação da autonomia da Coroa portuguesa. A cátedra e o púlpito, espaços privilegiados para o exercício do poder da palavra, conheceram, de modo mais ou menos velado ou mesmo explícito, o discurso da autonomia como desejo cada vez mais exequível, quanto maior era o descontentamento que de um modo geral se fazia sentir em todo o reino. Se as revoltas populares e os pequenos motins contribuíram para a maturação do movimento que eclodiria na Restauraçáo de 1640, os discursos e oraçóes, a poesia e outras expressóes literárias que faziam parte da vida académica e social de Coimbra, não tiveram responsabilidade menor, não só na maturação desse movimento, como também, mais tarde, na consolidação da Restauração da autonomia tão desejada. 
$\mathrm{Na}$ Universidade de Coimbra do séc. XVII, o 'homo eloquens' era efectivamente 'homo politicus' e o uso da palavra não só contribuiu para a definição dos destinos desejados para o reino, como foi responsável na construção de mitos que se revelariam eficazes na preparação de um Kairos propício à revolução que restauraria a Independência de Portugal como reino soberano.

Os frequentes actos públicos em que brilhava a palavra na vida académica, que se estendia da Universidade aos numerosos colégios que preparavam os seus alunos, ofereciam a ocasião para mover as razóes e os ânimos, para suscitar o desejo e a vontade, para estimular a adesão a determinadas ideias e correntes, por parte do que era uma verdadeira elite intelectual.

A canonização da Rainha Santa Isabel no ano de 1625 foi, sem dúvida, uma destas ocasióes, particularmente privilegiada. $\mathrm{Na}$ verdade, a figura da Rainha Santa Isabel beneficiava há muito de especial devoção em Coimbra, especialmente na Universidade. Por ocasião das festas em sua honra eram pronunciadas oraçóes latinas em seu louvor e compunham-se poemas, que hoje encontramos manuscritos nos códices 993 e 994 da Biblioteca Geral da Universidade de Coimbra. Estes códices constituem um documento da devoção da Companhia de Jesus à Rainha Santa, bem como do seu empenho na canonização da rainha cuja memória era muito celebrada na cidade e na universidade. Deles destacamos, no códice 993, a De vita et moribus Divae Elisabethae Lusitaniae Reginae historia, de Pedro 
Perpinhão, que seria depois publicada em 1609 em Colónia, ainda antes da sua canonização, portanto.

Foi, então, com grande entusiasmo que Coimbra recebeu a notícia da canonização desta Rainha cujas relíquias se guardavam no Mosteiro das Clarissas. Toda a cidade rejubilou e assistiu a vários dias de festa, a expensas do bispo da cidade. A Universidade associou-se, como se descreve na "Relação das Grandiosas Festas que na Cidade de Coimbra hoje por novo titulo ditosa Cidade fez o Illustrissimo Senhor Dó Ioão Manoel Bispo Conde, à Canonização de Sancta Isabel Rainha de Portugal"

"Entrou logo a cidade em suas festas que durarão seis dias. Começarão por hua encamizada em a noite de terça para quarta, estando a cidade toda ardendo em luminarias. Ouue Alcanzias, Touros, Comedias, Manilha, \& Canas. Não se calou nesta occasião da Canonização da Sancta Rainha a Illustre, inclyta, \& Real Universidade, antes com grandes premios conuidou os ingenhos que nella florescem a sairem com poesias, \& a fazerem dizer as Musas, não limitando a lingoa, mas dando a todas o campo, quer Latina, quer italiana, quer Espanhola: não falo na lingoa Portugueza, que essa, como mais eloquente, \& a materna deste Reyno, em que a Sancta Rainha reinou, a primeira era que se conuidaua." ${ }^{1}$

A Universidade festejava o que sentia como verdadeiramente 'seu' e promoveu, de sua parte, como se

1 Manuscrito anónimo que A. G. da Rocha Madail, 10 Conservador da BGU transcreveu e publicou na Revista literária $O$ Instituto, 90 (1936) 4-36. Cfr. p 61. 
pode ler, um certame poético que veio a publicar no ano seguinte juntamente com discursos latinos e sermóes em louvor da Rainha Santa. O Poeticum Certamen ${ }^{2}$ recolhe uma série de poemas hagiográficos, encabeçados pelo Poema epicum, siue heroicum ${ }^{3}$ do então sacerdote da Companhia de Jesus, o P. Francisco de Macedo ${ }^{4}$. É nesta composição poética hagiográfica que nos detemos para observar como poesia e hagiografia exprimiram a intuição do kairós oportuno à exaltação de sentimentos patrióticos e autonomistas que prepararam a Restauração de 1640.

A devoçáo e o culto dirigido a uma figura que se identificava com o reino de Portugal, mais ainda, com a coroa portuguesa, confirmada e reforçada pela canonização, que emanava de uma autoridade internacional como era Roma à altura, só podia contribuir para a identificação nacional com uma coroa soberana e autónoma, livre de qualquer hegemonia castelhana.

\section{O Poeta (fr.) Francisco de (Santo Agostinho) de Macedo}

A figura de Fr. Francisco de Santo Agostinho de Macedo e a sua obra filosófica foram já objecto de

${ }^{2}$ Sanctissimae Reginae Elisabethae Poeticum Certamen dedicat et consecrat Academia Conimbricensis, iussu illustrissimi D. Francisci de Brito de Menezes a consiliis Catholicae Maiestatis et eiusdem Academiae Rectoris, Coimbra, 1626.

${ }^{3}$ Este poema foi mais tarde reeditado na colecção do P. António dos Reis e Manuel Monteiro (1748: tomo VII, 78-94).

${ }^{4} \mathrm{~A}$ autoria das composiçôes poéticas não vem indicada na obra, mas os três primeiros poemas a que nos referimos vêm editados no Corpus ... op. cit. como da autoria do P. Francisco de Macedo. 
estudo de Ilídio de Sousa Ribeiro numa monografia que a Universidade de Coimbra publicou em $1952^{5}$. Interessa-nos aqui, porém, o jesuíta mestre de retórica, faceta também já estudada por Aníbal Pinto de Castro ${ }^{6}$, mais que o professor de filosofia que viria a ser um franciscano de assinalável actividade docente em Roma, Veneza e Pádua.

Francisco Macedo nasceu em 1596 e entrou para o noviciado da Companhia de Jesus, em Coimbra, no ano de 1610. Fez os estudos de Retórica no Colégio das Artes, bem como os de Filosofia e de Teologia. Em 1620, o P. Francisco Macedo era mestre de Retórica no Colégio de St. Antão, em Lisboa. Ensinou depois em Santarém (1625) e foi a notícia do seu talento que o levou a Madrid em 1628 para ensinar Retórica no Colégio Imperial. Em 1630 fez a profissão solene dos quatro votos.

Apesar da admiração que por ele nutria D. Filipe IV e das relaçóes que estabelecera com a corte de Madrid, o P. Macedo náo se inibiu de manifestar o seu inconformismo com a união das Coroas pelo que, em 1637, por ocasião de tumultos anti-castelhanos em Évora, acusado pelas palavras dos seus sermóes, se viu 'encerrado' na Casa Professa de São Roque, em Lisboa onde esteve até 1640. A sua permanência nesta casa, porém, não se relaciona apenas com aquela acusaçáo, mas também com a sua saída da Companhia para o que pediu autorização em 1638. Com a Revolução de 1640

5 lídio de Sousa Ribeiro (1952).

${ }^{6}$ Aníbal Pinto de Castro 2008: 66-70). 
começaria para o P. Macedo uma nova fase ao serviço da legitimaçáo da Dinastia de Bragança ${ }^{7}$. Logo em Fevereiro de 1641 partiu oculto com a embaixada de D. João IV a França, como agente secreto, mas também para dali se dirigir a Roma, ao Geral da Companhia, com o fito de alcançar a dispensa dos quatro votos que lhe permitiria professar noutra Ordem Religiosa. Regressado a Portugal, professou em 1642 na Província reformada de St. António da Ordem Franciscana, província da qual se veio depois a transferir em 1646 para a Província Observante.

Fr. Francisco de St. Agostinho de Macedo acompanhou várias missóes diplomáticas, a pedido de D. João IV, às principais cortes da Europa e foi nomeado cronista do reino em 1650. Posteriormente, o seu prestígio chegou a Roma onde foi professor no Colégio da Propaganda Fide, ensinando Controvérsia, ou Teologia Polémica, a pedido do Papa Alexandre VII, em 1656. Em 1660 foi o primeiro Professor de História Eclesiástica na Universidade de Roma La Sapienza. Em Setembro de 1667 defendeu conclusóes em Veneza e ocupou a cátedra de Filosofia Moral da Universidade de Pádua onde viria a falecer em 1681 .

\section{O Pro Elisabetha Regina Lusitanorum ... poema épico e hagiográfico}

Embora intitulado como 'épico' pelo poeta, na realidade, este poema é uma oratio em verso heróico,

${ }^{7}$ Sobre este aspecto veja-se Marques (1989). 
sem as rituais proposição e invocação, 'impostas' pela prática da epopeia renascentista. A matéria de louvor do herói reveste-se predominantemente da forma descritiva. Só ocasionalmente o poeta canta os 'feitos' de Santa Isabel, a heroína louvada no poema. Em cerca de 500 hexâmetros dactílicos (496), o P. Francisco de Macedo faz o elogio da Rainha Santa, recorrendo à descrição e louvor de um cortejo imaginário composto pelos monarcas do reino desde o início da nacionalidade até D. Sebastiáo, terminando depois com a entrada de Sta Isabel na Glória dos Céus e encerrando a composição com a peroração à pátria enlutada, para que enxugue as suas lágrimas e de novo erga a cabeça, pela mão da nova Santa que tem em seus altares.

A composição começa como um hino de louvor a Sta Isabel, à sua chegada como membro da corte celestial, ela que finalmente trará o descanso à pátria aflita e transformará esta idade de ferro em idade de ouro:

Venisti tandem Lux alma et debita nostris

Ah nimium curis, totiesque vocata Parentum

Nunc prece, nunc lacrymis; requiem allatura, decusque

afflictae patriae: quae ferrea tempora in aurum

convertes; qua nos propius respexit ab alto

Omnipotens Genitor, uultuque afflauit amico. ${ }^{8}$

Vieste enfim, doce auxílio, a nossos muitos cuidados [destinado,

${ }^{8}$ Reis e Monteiro (1748: VII 78 vv 1-6). 
tantas vezes invocada pelas preces e pelas lágrimas dos [nossos avós para trazer o descanso e a glória, à pátria aflita; tu, que hás-de converter em ouro esta idade de ferro, pois, por tua graça, Deus Pai Omnipotente volveu para nós, lá do alto, o seu olhar favorável.

O poeta abre a composição com os dois tópoi que lhe dão razão de ser: a canonização da rainha que os portugueses há muito queriam venerar nos altares e a graça da libertação da pátria que ela trará aos portugueses. Parece-nos clara a dupla leitura a fazer destes versos. A alegria da canonização é motivo de esperança para aqueles que pretendem repor a integralidade da soberania portuguesa, pondo fim à uniáo das duas coroas, contra a qual, na década de vinte, se vinha agudizando um geral descontentamento. A perda de Ormuz para os ingleses em 1621, a tomada de Salvador pelos holandeses em 1624, a crise de fome que se fez sentir em Maio de 1622, bem como o agravamento dos ataques dos holandeses sofridos pela mesma altura na Foz do Tejo e nas barras do Porto e de Aveiro, e ainda as incursóes de turcos e mouros na costa Algarvia que traziam a população em alvoroço, favoreceram certamente um cima de tensão anti-castelhana.

Esta mesma chave de leitura podemos mantê-la até ao final do poema. Na verdade, aquilo que o poeta trabalha como matéria épica, o carácter heróico de Santa Isabel e os Magnanimi Heroes que em cortejo triunfal nos céus a acompanham, traduz-se num olhar sobre os heróis nacionais do passado para, pela sua exaltação, 
estimular o aborrecimento do presente e projectar a esperança no futuro.

Do céu aberto, o poeta vê descer os heróis nascidos em melhores dias, em cujo reinado outrora se estabeleceu o império lusitano, heróis que nos evocam os feitos da rainha trazendo na mão os sinais e figuraçóes das suas virtudes, e os indícios do presente triunfo de Santa Isabel.

Fallor? An incipiunt portis se effundere apertis

Magnanimi Heroes, nati melioribus annis,

Sub quibus Imperium quondam hoc stetit : altior illis

Maiestas, speciesque angustior: undique corpus

Splendor obit Solem exuperans; intexta coronis

Sidera scintillant, capitum ornamenta; refulget

Dignior, et qualis Superos decet, oris imago.

Reginae hi recolunt ingentia facta, manuque

Virtutum argumenta ferunt, vitaeque prioris

Indicia ostentant, partae nunc praemia palmae, ${ }^{9}$

Mas, é uma ilusão, ou vejo eu que começam a avançar por [estas portas abertas

Heróis magníficos, nascidos em melhores tempos, em cujo reinado um dia este império se ergueu?

É superior a sua grandeza, mais nobre a sua aparência;

o esplendor que os cerca supera o sol

e entretecidas em suas coroas brilham as estrelas, ornameto [da sua fronte; resplandece mais grave a visão do seu rosto, como aos [Santos convém.

${ }^{9}$ Reis e Monteiro (1748: VII 79 vv 39-48). 
Eles trazem-nos à memória as obras sublimes da Rainha, carregando nas mãos os sinais das suas virtudes e ostentam os anúncios dessa vida futura e os prémios da [palma agora alcançada.

Dispensamo-nos de enumerar aqui todos esses heróis e referimos apenas dois dos mais emblemáticos. $\mathrm{O}$ cortejo abre com D. Afonso Henriques que ostenta uma coroa de espinhos, identificando-se assim com o milagre de Ourique. Seguem-se os seus sucessores, todos eles identificados com algo que simbolicamente os associa às virtudes da Rainha, fazendo-os como que participar delas. Entre estes merece destaque D. Manuel que o poeta reconhece pelo globo que traz na mão, aquele que venceu o oceano e os monstros do mar, que aos mundos desconhecidos levou o nosso estandarte, que subjugou a barbárie e os povos infiéis e que, ostentando o globo invoca sobre si a vocação universalista de Portugal.

D. João III, o cultor de Atenas e o novo fundador da Universidade, merece sempre especial destaque em todos os discursos académicos em Coimbra, também aqui nesta oratio em verso.

Encerram este cortejo triunfal dois heróis. Tratase do Cardeal D. Henrique, glória derradeira do reino lusitano, e de D. Sebastião. D. Henrique identifica-se pela veste cardinalícia que, no dizer do poeta, em algo se assemelha à tiara de Pontífice ${ }^{10}$, e traz num quadro

${ }^{10}$ Com efeito, o Cardeal D. Henrique, em 1555 obteve quinze votos na eleição papal. 
a representação da elevação de Santa Isabel aos altares. D. Sebastiáo, esse, vem envolto numa nuvem, em que o poeta divisa o espectáculo desolado de um fim de combate. As insígnias de Portugal estão por terra, a coroa real tombada, um rosto pálido, sujo de poeira, com os cabelos desalinhados pela face, jaz por terra. Estes versos são de intenso tom elegíaco, e prosseguem num Hino ao desejado:

\section{(...) Nec jam te absconde Sebaste,}

Laetitia o Regni breuis, o spes uana tuorum, I

$O$ desiderium, cura importuna, dolorquel

Aeternus, quanqum iustus (...) $)^{11}$

Não mais vos escondais D.Sebastião,

ó breve alegria deste reino, ó vã esperança dos vossos,

ó saudade, cuidado que não tem repouso, dor eterna, posto

[que justa.

O poeta, porém, vê que o fulgor daquele rosto reaparece, e divisa no seu olhar um sorriso. É que Santa Isabel, apiedada do sofrimento lusitano, exorta-o a esperar por melhores dias...

estende a mão àquele que jaz caído,

(...) a custo arrasta os seus membros enfermos,

soergue-o, apoiando-o, e de novo o eleva às alturas do poder; devolve-lhe o ceptro e a coroa:

${ }^{11}$ Reis e Monteiro (1748: VII 91 vv 381-384).. 
Ergo manum labenti offert, (...)

(...) uix et genua aegra trahentem

Sustentatque, leuatque, iterum extollit in altum

Imperii culmen; sceptrum, et diadema reponit. ${ }^{12}$

É então que Santa Isabel encerra este cortejo, transportada no seu carro triunfal. Acompanham-na os anjos, cantando hinos sagrados, e o céu abre as portas de par em par. Santa Isabel senta-se no trono, resplandecendo numa coroa de estrelas. Os últimos versos do poema são um hino de louvor e uma prece. Se Santa Isabel recorda ainda algum amor da mãe que na terra foi, cuide agora de Portugal:

Atque age tutelam Lysiae, et sub numine serua laeta tuo, et quam olim belloque, opibusque superbam Rexisti, fractam refice, atque attolle jacentem. ${ }^{13}$

Zelai, pois, pela defesa de Portugal, guardai-o sob o vosso [braço protector, a nação que outrora, na guerra, governaste soberba em sua [grandeza, agora alquebrada, restaurai-a, erguei-a, que jaz prostrada.

O poeta imagina já os efeitos da nova intercessão. Santa Isabel devolve a honra e o vigor ao reino da pátria.

Quid loquor? aut ubi sum? non Elisabetha iacentem

Eriget; erexit iam, atque ornamenta prioris

${ }^{12}$ Reis e Monteiro (1748: VII 91 vv 393-396).

${ }^{13}$ Reis e Monteiro (1748: VII 92 vv 434-436). 
Restituit famae, primaque in sede locauit:

Virtutemque decusque amissum reddidit, et nos

Degeneres genus ad patrium, roburque reduxit.

Nec iam Massylum gentes, Maurusiaque arua,

Proh dolor! et nostro recalentes sanguine campi;

Nec pestes pelagi insidiae, Algericae triremes:

Nec Batavum, tormentaque dira timorem

Incutiunt: plorat uersis gens impia fatis;

Elisabeth strages, infaustumque omen in illos

Conuertit; deflent sua funera, foeda per illos

Tempestas ruit effuso cum sanguine: nomen

Iam Lusitanum miseri horrescuntque, tremuntque. ${ }^{14}$

Mas, que digo eu? onde estou? Santa Isabel não há-de erguer [essa que jaz, pois ergueu-a já, restituiu-lhe as insígnias da sua glória primeira, colocou-a no seu trono antigo, devolveu-lhe a honra e a [glória perdidas, e a nós, indignos, de novo trouxe a raça e o vigor pátrios. Não mais os povos da Massília, ai dores!, não mais os [campos e as terras dos Mouros hão-de aquecer com o nosso sangue! não mais as desgraças [e as ruínas no mar nem as triremes dos piratas da Argélia! não mais as armadas [dos Batavos lançarão contra nós as suas tremendas máquinas de guerra e o terror. Mudada a sorte, lamenta-se agora essa ímpia nação.

Santa Isabel lança sobre eles a destruição e um terrível presságio. Já choram a sua ruína, abate-se sobre eles a desgraça terrível e o sangue derramado, e, miseráveis, tremem de pavor ao ouvir o nome dos portugueses.

${ }^{14}$ Reis e Monteiro (1748: VII 92-93 vv 437-450). 
No ânimo dos Lusos recrudescem a ira e a honra. Arrebatados pelas armas e pelo ardor de Marte vingarão a pátria e hão-de resgatar o seu nome que jaz sepulto, para que se erga do pó, rediviva, a sua glória.

At Lusis surgunt animis maioribus irae, Ignescitque pudor: rapiunt nos arma, calorque Martius; ulcisci patriam, reparare sepultum Nomen, ut exurgat rediuino e puluere fama. ${ }^{15}$

Era isto, ó Altíssimo, continua o poeta, que guardáveis para Portugal, depois de tantos anos de luto e sofrimento:

"Ó feliz geração a nossa, ó felicidade destes tempos, e felizes [de nós, a quem foi dado viver para ver a nossa Rainha acrescida ao [número dos santos."

O felix aetas, felicia tempora, nosque

Felices! quibus est permissum uiuere, cum iam Reginam caelo adscriptam, Diuumque relatam In numerum nidisse datum est! ${ }^{16}$

A felicidade que provém da canonização de Santa Isabel redime a dor do tempo presente que o poeta já vê transformado pela esperança. Finalmente, os seus últimos versos dirigem-se à Pátria enlutada, para que deponha as vestes fúnebres e enxugue as lágrimas dos seus olhos:

${ }^{15}$ Reis e Monteiro (1748: VII 93 vv 451-454).

${ }^{16}$ Reis e Monteiro (1748: VII 93vv 461-465). 
Ergo maesta Parens longo iam soluere luctu

Lysia, funereos habitus depone, grauesque

fletu attolle oculos ${ }^{17}$...

e de novo se levante, pela mão de Sta Isabel, no esplendor da sua coroa, tal como outrora a Europa a via: vencendo pela espada a África, rasgando o mar alto, chamando ao seio da Fé e à Lei de Cristo os povos longínquos da Ásia, aniquilando cidades, debelando tiranos, trazendo de todo o mundo nobres vitórias:

Talem te ore refert, qualem te Europa uidebat

Vastantem ferro Libyam, et maria alta secantem,

Extremosque Asiae populos, gentesque nefandas

Ad Fidei gremium, Christique ad iura uocantem:

Excindentem urbes, debellantemque Tyrannos,

Et claros domito referentem ex orbe triumphos. ${ }^{18}$

\section{Uma leitura política deste poema hagiográfico}

É evidente a leitura política a fazer deste texto. A figura derrotada que Santa Isabel ergue, a quem devolve o aspecto real, a quem impóe de novo o ceptro e a coroa, começa por ser D. Sebastiáo, moribundo, no campo de batalha, e acaba por ser a própria terra Lusa a quem depois o poeta se dirige até ao final do poema.

${ }^{17}$ Reis e Monteiro (1748: VII 94 vv 475-477).

${ }^{18}$ Reis e Monteiro (1748: VII 94). 
As figuras que vemos desfilar são heróis do passado sobre quem o poeta projecta a excelência, como se pertencessem a uma idade de ouro. A convicção da superioridade e excelência dos monarcas portugueses não é exclusiva deste período da nossa história ${ }^{19}$, mas ganha nele um valor social e politicamente mais pertinente. Os heróis que vemos desfilar preparam um momento central, fora dos limites do tempo cronológico, o 'momento' em que Santa Isabel ergue da ruína o último monarca do desfile, D. Sebastião. Depois da leitura dos passos que citámos, compreende-se perfeitamente o silêncio com que o poeta omite os reis da dinastia filipina. ${ }^{20}$ Embora legitimamente aclamados, não os identificava a nação comum aos portugueses, cuja consciência colectiva se vinha apurando. Além disso, a crise geral que se fazia sentir reforçava o entendimento dos soberanos da dinastia filipina como 'reis estrangeiros'. Este entendimento faz-se acompanhar naturalmente de uma atitude hostil, como curiosamente antevira D. Jerónimo Osório no De Regis institutione. ${ }^{21}$

O jovem rei D. Sebastião e o Cardeal D. Henrique

19 Testemunha-o, por exemplo, o exórdio do De Regis Institutione et disciplina de D. Jerónimo Osório, tratado que dedica a D. Sebastião. Cfr. Soares (1994 : 298).

${ }^{20}$ Três anos depois da publicação desta colectânea, em 1629, na Oração de Sapiência que proferiu na Universidade, o P. Francisco Machado SJ, no habitual tópico de elogio do Rei, escolhe, para louvar, D. João III, omitindo D. Filipe. Veja-se Urbano (2001: 68-71).

${ }^{21}$ Cfr. Soares (1994: 400): "Se a semelhança de vida e de costumes atrai a fidelidade e o amor do povo, a ausência dessas afinidades, que o rei estrangeiro encarna, afasta o consenso unânime e a afeição dos súbditos, indispensáveis ao bem-estar e à estabilidade." 
são inicialmente referidos a par e, logo depois, este último dilui-se no destaque dado ao primeiro. Todo o poema é um crescendo orientado para o momento em que o motivo principal da composição, a canonização e o triunfo da Rainha, escatologicamente se transforma no motivo da redenção da pátria que recupera a integralidade da soberania e se liberta das agressóes externas de mouros e holandeses. ${ }^{22}$

Todo o poema se desenvolve no ambiente fantástico e maravilhoso da visão onírica do poeta, bastante ao gosto da estética barroca. Em última instância, o poema resulta de uma revelação mística. Os heróis são-nos apresentados pelas virtudes próprias ou da Rainha, herói principal do poema. Não assistimos ao decurso da sua acção no tempo, pois eles ultrapassaram já os limites do tempo cronológico. O maravilhoso actuante é, naturalmente, o maravilhoso cristão, omnipresente no poema, e a mitologia é a nacional. Podemos dizer que se trata aqui de um poema épico-místico em que náo conseguimos distinguir a crença nacional da religiosa, porque as duas são inseparáveis. Patriotismo e religiáo são aqui intrinsecamente dependentes.

A esta altura era já corrente em certos meios a ideia, que se veio a generalizar e propagandear depois da Restauração, de que Portugal era detentor de um destino sagrado que consistia em última instância em evangelizar o mundo. Lembremos que Portugal nasceu

${ }^{22}$ Note-se que data do ano da canonização da Rainha, um ano antes da publicaçáo do poema, a reconquista da Baía, até então dominada pelos holandeses. 
em ambiente de reconquista, de cruzada, e que depois se deixou surpreender com as suas próprias capacidades de expandir a cultura latina e cristã num movimento que foi de abertura de novas vias nas relaçóes internacionais, de expansão económica, de proselitismo religioso, movimento interrompido por uma crise geral da nação que se conjugou com a uniáo das coroas de Portugal e Espanha e seus efeitos agravantes naquela crise. $\mathrm{O}$ período do chamado 'domínio filipino' é fecundo na criação ou recuperação de mitos nacionais que contribuem decisivamente para o fortalecimento da consciência colectiva de independência e de soberania. Entre as profecias e as revelaçóes mais variadas, destacam-se o Milagre de Ourique e o Sebastianismo, nas suas diversas tonalidades. No poema do P. Francisco Macedo é o mito do messianismo sebastianista que sustenta a mensagem final e revela o seu significado último, embora o milagre de Ourique esteja também muito presente, não só na função identificadora de $\mathrm{D}$. Afonso Henriques, que abre o cortejo, mas também no pressuposto, presente no poema e mais explícito no final, da vocação universalista de Portugal, um novo 'povo eleito', chamado desde a sua fundação a convocar as naçóes ao seio da Fé Cristã.

$\mathrm{Na}$ verdade, se o milagre de Ourique, oportunamente recuperado neste período, revelava uma fundação divina da pátria detentora de uma missão universal e profetizava a perda da independência e posterior recuperação, entendia-se assim que a opressão que recentemente se agudizava era transitória, 
alimentando-se desse modo a esperança. A evocação deste mito, como afirma João Francisco Marques, constituiu mais tarde, nas lutas de resistência depois da revolução de 1640, 'um expoente dinâmico para a crença no triunfo' ${ }^{23}$.

O mito sebastianista, que nesta altura (47 anos depois de Alcácer-Quibir) não seria já a crença no regresso real do Desejado, surge aqui intimamente associado ao Milagre de Ourique, na medida em que este aponta para o carácter transitório deste período de crise. A recuperação de $\mathrm{D}$. Sebastiâo (o próprio ou a sua revivência num herdeiro da Casa de Bragança) constitui o momento de superação dessa crise. Restituídos o ceptro e a coroa a seu rei, e depois do triunfo da Rainha Santa, o poeta pode cantar, por antecipação, a vitória da nação Lusa a quem Santa Isabel também estendeu a mão. D. Sebastião identifica-se plenamente com o reino. A ruína de um foi a ruína do outro. Por isso era compreensível que a redenção nacional passasse pelo resgate simbólico do seu último rei legítimo (do ponto de vista do poeta). Esta redenção é possível graças à protecção divina por intercessão da Santa, que significativamente é também Rainha, cujas virtudes de piedade e caridade vimos desfilar ao longo do poema.

A longa existência do mito sebastianista, se nele subsumirmos a notável expectativa que a nação colocou no nascimento de $\mathrm{D}$. Sebastiáo a ponto de lhe dar o cognome de $O$ Desejado, ${ }^{24}$ teve neste período grande

${ }^{23}$ Marques (1989:245).

${ }^{24}$ Filho póstumo do último dos nove filhos que D. João III 
repercussão, sobretudo a partir de 1625, quando aumenta no reino o culto profético e a este se associa um cada vez mais geral eco de oposição à união das coroas ibéricas. ${ }^{25}$

Textos como este não só deixavam transparecer o pensamento dos seus autores, como a oscilação dos movimentos políticos, e permitem-nos hoje ajuizar das correntes dominantes no meio em que foram escritos e publicados.

Embora formalmente, como acima dissemos, o poema não use as rituais propositio e invocatio, nem faça uma narratio, compreendemos, no contexto da concepção literária do seu tempo, a designação que o autor lhe dá de poema épico, não só pelo uso do hexâmetro dactílico melhor adaptado à nobreza do tema, mas também pela linguagem e pela matéria. $\mathrm{O}$ louvor da Rainha, agora Santa, transforma-se no louvor dos heróis fundadores de um país e do seu império, heróis que por sua vez são subsídios para o louvor daquela. Num primeiro plano a epopeia faz-se da gesta do herói, neste caso as virtudes da piedade, pobreza e caridade da Rainha, bem como dos seus esforços por conseguir a paz dentro do reino e, num segundo plano, que se vai tornando cada vez mais claro até se explicitar no final, desenrola-se a epopeia de um país que de tão largo império vê perdida a sua soberania,

viu morrer, D. Sebastião não podia deixar de ser tão esperado, e toda a sua existência foi naturalmente marcada pela necessidade de garantir sucessão.

${ }^{25}$ A propósito destas esperanças de autonomia veja-se Serrão, (1979 : IV 104-106). 
esperando, embora, na sua recuperação. A união dos dois planos faz-se claramente na parte final do poema, quando a canonização de D.Isabel não é apenas motivo de alegria per se (e náo esqueçamos o significado político da canonizaçáo da Rainha, como elemento de prestígio diante da Europa católica), mas também (e porque não sobretudo) por, no plano textual, estar eminente a restituição daquela soberania ao país. $\mathrm{O}$ poema, usando embora a descrição da imagem desolada do reino, é sobretudo uma afirmação de optimismo, de confiança no momento (no kairós) na graça e na intercessão do herói principal, Santa Isabel.

Encarnando um desígnio hagiográfico tipicamente medieval que aliava as virtudes da mulher, mãe, soberana, promotora da paz e monja, a figura de Santa Isabel de Aragão, no séc. XVII, proporcionou ao P. Macedo o motivo necessário para a exaltação de sentimentos identitários patrióticos, numa composição poética eloquente e capaz de mouere o 'auditório' a sentir com o poeta. $\mathrm{O}$ mestre de Retórica, e poeta novilatino, é simultaneamente o homo eloquens e o homo politicus.

A identificação com Santa Isabel não corresponde apenas a uma identidade religiosa e espiritual; ela é também social, cultural e política. Ela é expressão inspiradora de uma consciência colectiva, neste caso nacional 'avant la lettre'. Sem retirar uma vírgula ao valor universal da figura modelar da Rainha, reconhecido na canonização oficial, assistimos a um fenómeno de 'nacionalização' da santa. O que náo deixa de ser curioso, 
tanto mais que, como é sabido, D. Filipe III instou junto do Papa no sentido de concluir a canonizaçáo da Rainha, há muito venerada pelos portugueses, e à qual ele se sentia ligado por laços de sangue. ${ }^{26}$ Não obstante, esta mesma canonização é lida como sinal de protecção dos portugueses, com a necessária ruptura em relação à coroa castelhana.

Nesta oratio a que a mestria retórica de Francisco Macedo confere uma voz eloquente e eficaz, Santa Isabel é assumida, usando a expressão de Reginald Gregòire, como 'corresponsável do presente e do futuro da sua comunidade', no caso, o reino de Portugal. ${ }^{27}$

O trabalho de investigaçáo que deu origem a este estudo constitui a principal matéria de um artigo publicado na Humanitas 53 (2001) 343-364.

${ }^{26}$ Brásio (1957: 10-11).

27 Expressão que o especialista em Hagiografia utiliza para caracterizar a relação entre o santo e a 'sua' cidade. Cfr. Gregòire, (1996: 396). 


\section{BibLIOGRAFia}

Brásio, António (1957), Novos documentos para a História da Rainha Santa Isabel, Coimbra.

Castro, Aníbal Pinto (2008), Retórica e Teorização literária em Portugal, 2a ed. Lisboa, Imprensa Nacional Casa da Moeda.

Gregòre (1996), Reginald, Manuale di Agiologia, Fabriano.

Madail, A. G. da Rocha (1936), "Relação das Grandiosas Festas que na Cidade de Coimbra hoje por novo titulo ditosa Cidade fez o Illustrissimo Senhor Dó Ioão Manoel Bispo Conde, à Canonização de Sancta Isabel Rainha de Portugal" O Instituto, 90 4-36.

Marques, João Francisco Marques (1989), A Parenética Portuguesa e a Restauração,(1640-1668), Porto, 2 vol.

ReIs, António e Monteiro, Manuel (1748), Corpus Illustrium Poetarum Lusitanorum qui latine scripserunt, Lisboa, , tomo VII.

Ribeiro, Ilídio de Sousa (1952), Fr. Francisco de Santo Agostinho de Macedo, um filósofo escotista português e um paladino da Restauração, Coimbra.

Serrão, Joaquim V. Serrão (1979), História de Portugal, (1580-1640), Verbo, Póvoa do Varzim. 
SoAres, Nair Castro (1994), O Principe Ideal no séc. XVI e a obra de D. Jerónimo Osório, INIC, Coimbra.

Urbano, Carlota Miranda (2001), A oração de Sapiência do P. Francisco Machado, Estudo. Tradução. Comentário. Lisboa, Colibri. 